\title{
INFORME NACIONAL: Ejecución provisional de la sentencia civil en Perú(*)
}

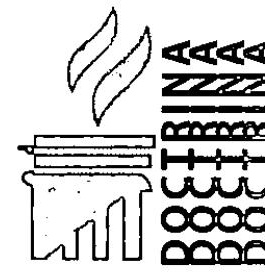

Adrian Simons Pino ${ }^{(* *)}(* * *)$

Profesor de la Maestría de Derecho Procesal en la Universidad Peruana de Ciencias Aplicadas. Profesor del Curso de Derecho Procesal Civil en la Universidad de Lima.

Miembro del Instituto Iberoamericano de Derecho Procesal y de la Asociación Internacional de Derecho Procesal. Miembro del Consejo Consultivo de la Revista ADVOCATUS.

\section{SUMARIO:}

I. Introducción.

II. La ejecución provisional de la sentencia civil (actuación de la sentencia impugnada):

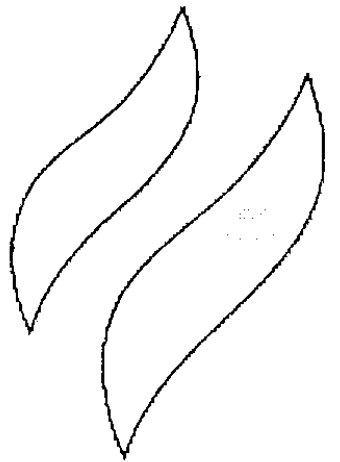

1. Definición;

2. Intereses en conflicto y finalidad satisfactiva;

3. Revocatoria de la sentencia.

III. La actuación de la sentencia impugnada en el Perú presente:

1. Regulación en materia civil y comercial;

2. Regulación en materia procesal constitucional;

3. Instituciones afines: medida cautelar temporal sobre el fondo.

IV. La actuación de la sentencia impugnada en el Perú futuro:

1. Ceriajus;

2. Proyecto de reforma elaborada por el profesor Juan Monroy Gálvez.

v. Conclusiones.

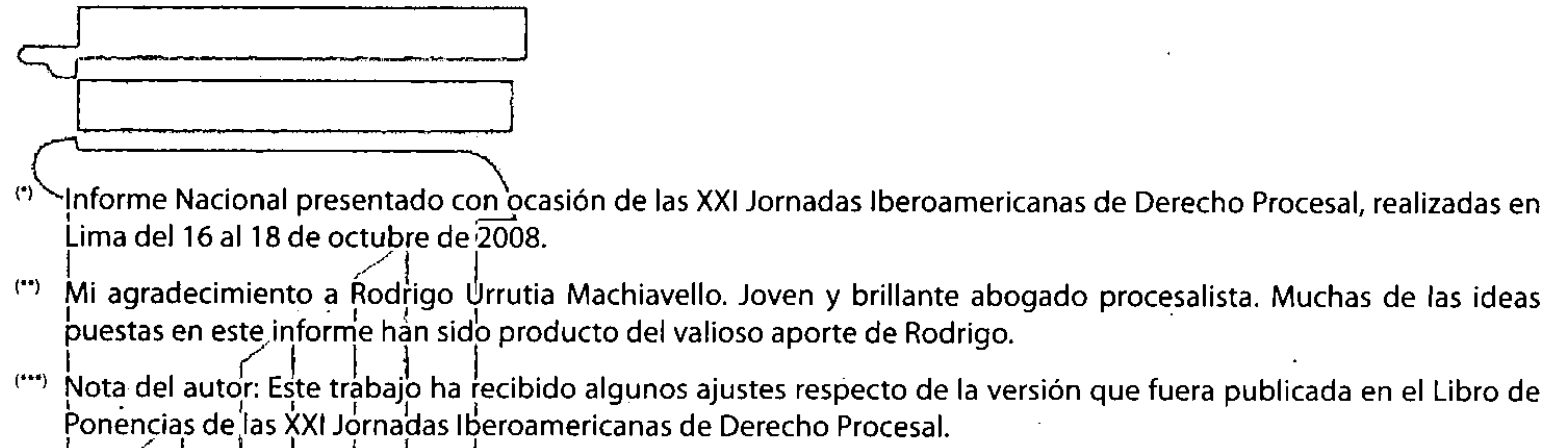




\section{INTRODUCCIÓN}

Históricamente, la legislación peruana en materia procesal civil ha estado más cerca de lo "procedimental" que de lo "procesal" en sentido estricto. La reforma procesal en Perú se llevó a cabo, recién, en el año 1993, con la entrada en vigencia del Código Procesal Civil; es decir, noventa años después del discurso de Chiovenda en la Universidad de Bolonia (1903), y después de más de un siglo de la época en que se rendía culto al "procedimiento" puro. En efecto, su inmediato antecesor, el Código de Procedimientos Civiles de 1912, constituyó una norma orientada a establecer un mero cúmulo de reglas sin mayor sustento doctrinal y carente de criterio sistemático alguno.

Sería recién a partir de 1993 que el Perú haría una apuesta científica e ideológica en materia procesal. De ahí que nuestro Código Procesal Civil haya asumido una concepción publicistica del proceso, orientada a entregar al Juez una función que va más allá de aquella de simple componedor de conflictos (como aquel mero aplicador de leyes de la Francia del siglo XVI). La apuesta fue sencilla y a la vez complicada: un Juez director del proceso' es el presupuesto indispensable para una decisión materialmente justa, siendo para ello necesario privilegiar el nuevo rol del Juez, preocupado por aproximarse a la verdad y por la calidad de sus decisiones. ${ }^{2}$
Asimismo, el Código Procesal Civil peruano puso en manos del Juez - $y$, evidentemente, de las partes- una serie de institutos procesales que pasaron desapercibidos por la tradicional visión civilista del derecho peruano. Tales institutos, en algunos casos, "nuevos"y otros casos"renovados", tuvieron un reconocimiento científico en el ordenamiento procesal y de ahí que el nuevo Código tuviera una marcada línea científica, a diferencia de su antecesor, con ordenamiento pre-científico.

Dos ausencias importantes a lo largo de casi cien años y que ahora se encuentran presentes a partir de la reforma procesal fueron: i) la intervención de terceros-aquellos que, formando parte de la relación material solicitaban su incorporación al proceso recibían por respuesta el categórico "no ha lugar por no ser parte" - ii) y la tutela cautelar innovativa y de no innovar -la única medida cautelar regulada por el Código de Procedimientos Civiles era el embargo, que permitía una figura similar a la del secuestro denominada "embargo con desposesión"-.

Sin embargo, nuestra reforma "adolescente" está por cumplir quince años. Por ello, es posible apreciar que así como ciertas instituciones fueron introducidas al sistema procesal peruano de manera casi completa y sin muchos reparos, ciertas otras instituciones "novedosas"3 han sido incorporadas con precaución, y ese es el caso de la actuación de la sentencia impugnada.

1 La función del juez como director del proceso se encuentra taxativamente reconocida en el artículo II del Título Preliminar del Código Procesal Civil vigente:

"Articulo II.-Principios de dirección e impulso del proceso:

La dirección del proceso está a cargo del Juez, quien la ejerce de acuerdo con lo dispuesto en este Código. El Juez debe impulsar el proceso por si mismo, siendo responsable de cualquier demora ocasionada por su negligencia. Están exceptuados del impulso de oficio los casos expresamente señalados en este Código".

2 Asi se aprecia en el artículo III del Título Preliminar del Código Procesal Civil:

"Articulo ll. - Fines del proceso e integración de la norma procesal.

El Juez deberá atender a que la finalidad concreta del proceso es resolver un conflicto de intereses o eliminar una incertidumbre, ambas con relevancia juridica, haciendo efectivos los derechos sustanciales, y que su finalidad abstracta es lograr la paz social en justicia (...)".

3 Decimos novedosas en el sentido cronológico más no histórico. La ejecución de la sentencia impugnada resulta ser una institución novedosa en Perú, pero no lo es en materia procesal y así lo ha explicado Monroy Gálvez: "El caso de la actuación de la sentencia impugnada es singular. No se inserta dentro de las llamadas nuevas técnicas procesales sino, 
Es importante indicar que la actuación de la sentencia impugnada se opone al efecto suspensivo de la apelación. Esta última constituye la regla general adoptada por nuestro ordenamiento procesal -artículo $371^{4}$ del Código Procesal Civil-, en virtud del cual si se interpone recurso de apelación contra una sentencia o un auto que da por concluido el proceso, la eficacia inmediata de la sentencia o auto quedará suspendida hasta que se resuelva la apelación.

Mientras que, por regla general, el beneficiado de una sentencia debe postergar su ejecución hasta que se decida de modo definitivo y favorable la impugnación interpuesta, mediante la actuación de la sentencia impugnada es posible que esta se ejecute a pesar de no haber adquirido la calidad de firme.

En el Perú, como veremos más adelante, la actuación de la sentencia impugnada no ha sido regulada, salvo, para supuestos limitados en donde el interés en conflicto va más allá de los netamente patrimoniales. Sin perjuicio de ello, en aquellos casos en donde se discuten derechos infungibles, distintos a los del alimentista, el ordenamiento procesal peruano regula las medidas cautelares "innovativas", de "no innovar" y las "temporales sobre el fondo". Si bien las medidas cautelares antes mencionadas constituyen instrumentos de tutela distintos de aquel que es materia del presente Informe Nacional, cierto es que existen muchas coincidencias en cuanto a sus efectos $y$ fines. ${ }^{5}$

Finalmente, el presente Informe Nacional consistirá en exponer el instituto de la Ejecución Provisional de la Sentencia civil en el Perú, a partir de su presente (regulación y supuestos a los cuales se aplica) y su futuro (propuestas de reforma). Asimismo, haremos breve referencia a aquellas instituciones afines que permiten a las partes obtener tutela provisionalmente.

\section{LA EJECUCIÓN PROVICIONAL DE LA SENTENCIA CIVIL (ACTUACIÓN DE LA SENTENCIA IMPUGNADA)}

\section{Definición}

Ensayando una definición -con los riesgos que ello implica- podemos decir que la ejecución provisional de la sentencia civil-conocida por la doctrina peruana con el nombre de "actuación de la sentencia impugnada" - es aquel supuesto en el cual una sentencia, a pesar de no haber adquirido la calidad de firme, por encontrarse impugnada o porque el plazo para impugnar aún no se ha cumplido ${ }^{6}$, es susceptible de ejecución conforme a sus términos.

En la mayoría de casos donde este instituto se aplique, estaremos frente a ejecución de sentencias de "condena" ${ }^{\prime}$, en virtud de las cuales una

como muchas de ellas, sólo consiste en una recuperación de un instituto desarrollado hace mucho tiempo y en distintos ámbitos sin que haya alcanzado no sólo un desarrollo uniforme, sino un reconocimiento apenas limitado de sus posibilidades que, de nuestro lado, pensamos que si las tiene si se emplea sujetándola a una normativa y desarrollo doctrinal que aprecie su verdadera importancia, sin extremismos optimistas ni pesimistas". MONROY GALVEZ, Juan, La Actuación de la Sentencia Impugnada. En: Revista Peruana de Derecho Procesal, No. 5, 2002, pp. 199-200.

4 Artículo 371.- Procedencia de la apelación con efecto suspensivo.

"Procede apelación con efecto suspensivo contra las sentencias y autos que dan por concluido el proceso o impiden su continuación, y en los demás casos previstos en éste Código".

5 Nuestro ordenamiento procesal cautelar se puede clasificar en dos grandes grupos: la tutela cautelar coincidente y la no coincidente. A través de la primera se puede adeiantar, total o parcialmente, los efectos de la futura decisión y, la segunda, sin tener relación con el objeto de la controversia asegura la eficacia de la decisión definitiva (por ejemplo: embargo).

6 Evidentemente, si el plazo para apelar se cumple sin que la apelación haya sido interpuesta, estaremos frente a un supuesto de ejecución de sentencia en el sentido clásico.

7 Una sentencia, en función à sus efectos, puede ser "meramente declarativa", "constitutiva" y de "condena." Entendemos por sentencias meramente declarativas aquellas que, poniendo fin a una crisis de certeza, concluyen o con-

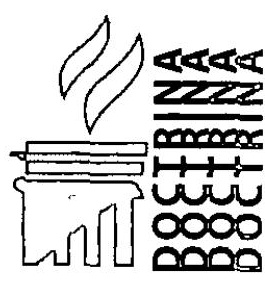


de las partes deberá cumplir con una prestación de dar, hacer o no hacer. Cierto es también que, en la medida que la realidad siempre habrá de adelantarse al derecho, no sería apropiado concluir que lo expuesto resulta ser una regla inmutable. Que la actuación de la sentencia impugnada sea viable en los procesos donde se expiden sentencias de condena, no excluye que dicho enunciado deba ser reevaluado constantemente, a la luz de las particularidades de cada caso.

\section{Intereses en conflicto y finalidad satisfactiva}

Consideramos que la ejecución provisional de la sentencia impugnada no colisiona con el principio/derecho a la doble instancia o grado. Ello debido a que el derecho de la parte perdedora a impugnar no se ve restringido. La sentencia puede ser impugnada, y eventualmente revocada, sin embargo, y en tanto la revocatoria no se verifique, se permite al vencedor exigir que se cumpla con lo dispuesto en la sentencia.

Permitir la ejecución de la sentencia a pesar que esta ha sido impugnada importaría quebrar la regla general referente a los efectos que sobre la sentencia impone la interposición de un medio impugnatorio. ${ }^{8}$ Si la apelación traía por consecuencia suspender los efectos de la decisión final, con el instituto que es materia del presente informe, dicha consecuencia desaparece; sin embargo, el derecho a impugnar permanece intacto.

Hemos visto que, por un lado, la ejecución de la sentencia impugnada no supone la restricción del derecho a la doble instancia o grado. Corresponde luego apreciar cómo es que la ejecución de la sentencia impugnada responde al interés de brindar eficacia real a lo decidido en primera instancia. Sin duda, una sentencia, por más favorable que sea, perderá toda utilidad práctica si carece de fuerza suficiente para trasladar sus efectos, desde el ámbito del proceso hacia el ámbito de la realidad.

Finalmente, mediante la ejecución de la sentencia impugnada se traslada a la parte impugnante los costos que pueden ser causados por la demora en el trámite de la apelación, a fin de beneficiar a la parte vencedora, en la medida que esta última no tendrá que esperar a que la apelación sea resuelta favorablemente para luego ver efectivizado su derecho. Ello debido a que, como ya adelantamos, la finalidad de la actuación de la sentencia impugnada no es otra que hacer efectivo aquello que se decidió en la sentencia, sin las dilaciones propias del trámite de la impugnación con efecto suspensivo, garantizando un proceso satisfactivo, en el sentido que el mandato contenido en la sentencia surta efectos y satisfaga la necesidad especifica de tutela de quien se vio en la necesidad de demandar.

\section{Revocatoria de la sentencia}

Luego de que se produce la ejecución de la sentencia impugnada, dos escenarios son posibles: i) que la sentencia sea confirmada, con lo cual la finalidad del instituto quedaría cumplida, dado que el derecho del victorioso se vio satisfecho oportunamente; ii) o que la sentencia sea revocada, con lo cual se verificaría un perjuicio en contra del ejecutado.

En este último escenario será necesario retroceder sobre nuestros pasos y restituir al obligado aquello que entregó, o resarcirle por aquello que hizo o dejó de hacer, en virtud del mandato contenido en la sentencia. En ese sentido, queda claro que uno de los rasgos que define

firman una situación preexistente respecto de la cual no existía consenso entre las partes ("accertamento"). Una sentencia constitutiva será aquella que crea una nueva situación juridica, modificando la preexistente y, finalmente, por sentencia de condena, entendemos aquel pronunciamiento jurisdiccional que tiene por objeto el cumplimiento de una prestación de dar, hacer y/o no hacer.

8 En el Perú, el efecto suspensivo es compartido por los recursos de apelación y casación. 
- o debería definir- la actuación de la sentencia impugnada es la "reversibilidad" del mandato que se ejecuta o, dicho de otro modo, la ausencia de "irreversibilidad".

\section{LA ACTUACIÓN DE LA SENTENCIA IMPUGNADA EN EL PERÚ PRESENTE}

\section{Regulación en materia civily comercial}

Como indicamos en las líneas precedentes, la actuación de la sentencia impugnada aparece regulada en Perú para determinados supuestos, considerados socialmente relevantes. En ese sentido, el instituto no encuentra reconocimiento para cuestiones civiles y comerciales de contenido netamente patrimonial.

La norma que regula la institución en el Código Procesal Civil es aquella contenida en el artículo $566^{\circ}$, referente a los procesos de Familia, y específicamente en aquellos donde se disponga la obligación de alimentos. En efecto, la norma señala que en aquellos procesos donde se emita sentencia en primer grado y se establezca como obligación el pago de una pensión de alimentos, esta deberá ser ejecutada conforme a sus términos, aún a pesar de haber sido impugnada, y sin que sea necesario que el beneficiado con la sentencia constituya garantía alguna destinada a asegurar el posible daño que pueda causar la actuación anticipada de una sentencia posteriormente revocada.

Ahora bien, mediante el artículo $569^{10}$ del Código Procesal Civil se regula el supuesto de que la sentencia sea revocada por el superior. En dicho escenario se establece la obligación del beneficiado indebidamente con la pensión de alimentos de restituir al apelante aquello que fue pagado, incluyendo los intereses aplicables.

Es cierto que, en la medida que la prestación de alimentos tradicionalmente constituye una obligación de dar suma de dinero, podría afirmarse que se trata de una obligación de naturaleza patrimonial y, sobre la base de dicha premisa, concluirse que cualquier obligación de pago debería ser susceptible de los beneficios que otorga el instituto objeto del presente Informe Nacional.

Sin embargo, tal posición no es sostenible. El hecho de que los alimentos puedan ser cuantificados en dinero es, finalmente, un dato intrascendente cuando lo comparamos con la relevancia de su efectivo cumplimiento a favor de los alimentistas. Se trata de un derecho que exige una respuesta inmediata por parte del aparato de justicia, aún si, a pesar de ello, se

9 Artículo 566.- Ejecución anticipada y ejecución forzada.-

"La pensión de alimentos que fije la sentencia debe pagarse por periodo adelantado y se ejecuta aunque haya apelación. En este caso, se formará cuaderno separado. Si la sentencia de vista modifica el monto, se dispondrá el pago de éste. Obtenida sentencia firme que ampara la demanda, el Juez ordenará al demandado abrir una cuenta de ahorros a favor del demandante en cualquier institución del sistema financiero. La cuenta sólo servirá para el pago y cobro de la pensión alimenticia ordenada. Cualquier reclamo sobre el incumplimiento del pago serd́ resuelto con el informe que, bajo responsabilidad, emitirá la entidad financiera a pedido del juez sobre el movimiento de la cuenta. Asimismo, en reemplazo de informe pericial, el Juez podrá solicitar a la entidad financiera que liquide el interés legal que haya devengado la deuda.

Las cuentas abiertas única y exclusivamente para este propósito están exoneradas de cualquier impuesto.

En los lugares donde no haya entidades financieras, el pago y la entrega de la pensión alimenticia se hará en efectivo dejándose constancia en acta que se anexará al proceso".

10 Artículo 569.- Demànda infundada.-

"Si la sentencia es revocada declarándose infundada total o parcialmente la demanda, el demandante está obligado a devolver las cantidades que haya recibido, más sus intereses legales con arreglo a lo dispuesto en el Artículo 567". 
quiebra con la "tradición" del efecto suspensivo en la apelación. De ahí que el legislador haya optado por aplicar el instituto específicamente a estos casos, pues siempre será preferible trasladar al apelante el costo que implica que se revoque la sentencia $y$, a pesar de ello, haber cumplido anticipadamente con el pago de alimentos, que trasladar a los alimentistas el costo que implica esperar a que la sentencia sea confirmada para que, recién, puedan recibir aquello que les corresponde.

Es cierto que existen otras situaciones de conflicto que una vez trasladadas al ámbito procesal merecerían la aplicación del instituto. Sin embargo, se ha optado por aplicar de manera progresiva la actuación de la sentencia impugnada, únicamente a ciertos supuestos específicos, a fin de evitar que su aplicación generalizada sea más perjudicial que beneficiosa. Nosotros coincidimos con tal posición "conservadora".11

\section{Regulación en materia procesal constitucional}

El legislador ha sido coherente con su posición de aplicar con precaución el instituto de la actuación de la sentencia impugnada, únicamente a determinados supuestos.

Siguiendo la línea de aplicar el instituto a aquellos derechos de gran trascendencia social -como los derechos constitucionalestenemos que el legislador del Código Procesal Constitucional Peruano -primero del Perú y de Sudamérica ${ }^{12}$ - ha regulado adecuadamente la posibilidad de actuar anticipadamente las sentencias de primer grado expedidas en el marco de los procesos constitucionales.

En efecto, la actuación de la sentencia impugnada aparece regulada el artículo $22^{13}$ del Código Procesal Constitucional, que ordena que las

11 Respecto a la aplicación generalizada del instituto, MONROY GẢLVEZ señala que la actuación de la sentencia impugnada resulta ser "una institución que nos parece bondadosa, aunque, admitimos que una apertura a su uso sin parámetros normativos o jurisprudenciales, más o menos explicitos, puede ser peligrosa". MONROY GALVEZ, Juan, Ob.Cit., p. 219.

Siguiendo la misma línea, MONROY PALACIOS señala: "En nuestro país dicha categoria aún no es conocida pues reina, de manera absoluta, el efecto suspensivo sobre la impugnación de sentencias. En otros ordenamientos (como Brasil e Italia) la situación es distinta, en la medida que persiste una tendencia a generalizar, precisamente, la opción inversa. Por nuestra parte, consideramos que es necesaria la apertura del instituto, sin embargo, aquélla debe efectuarse de manera mesurada, es decir, dirigida inicialmente a supuestos especificos. No es bueno repetir lo desconocido sin analizar el impacto que figuras alienigenas provocarán sobre nuestro aún incipiente sistema de justicia. Nadie quiere revivir la 'orgía legisfativa' (Carpi) que hoy se padece en Italia, aunque, ciertamente, nosotros la hemos venido padeciendo a nuestra manera". MONROY PALACIOS, Juan José, La Tutela Procesal de los Derechos, Palestra Editores, Lima, 2004.

12 En estricto el primer Código Procesal Constitucional es aquel de la provincia argentina de Tucumán, sin embargo, su aplicación se encuentra limitada geográficamente a dicha provincia.

13 Artículo 22.- Actuación de sentencias.-

"La sentencia que cause ejecutoria en los procesos constitucionales se actúa conforme a sus propios términos por el juez de la demanda. Las sentencias dictadas por los jueces constitucionales tienen prevalencia sobre las de los restantes órganos jurisdiccionales y deben cumplirse bajo responsabilidad.

La sentencia que ordena la realización de una prestación de dar, hacer o no hacer es de actuación inmediata. Para su cumplimiento, y de acuerdo al contenido especifico del mandato y de la magnitud del agravio constitucional, el Juez podrá hacer uso de multas fijas o acumulativas e incluso disponer la destitución del responsable. Cualquiera de estas medidas coercitivas debe ser incorporada como apercibimiento en la sentencia, sin perjuicio de que, de oficio o a pedido de parte, las mismas puedan ser modificadas durante la fase de ejecución.

El monto de las multas lo determina discrecionalmente el Juez, fijándolo en Unidades de Referencia Procesal y atendiendo también a la capacidad económica del requerido. Su cobro se hará efectivo con el auxilio de la fuerza pública, el recurso a una institución financiera o la ayuda de quien el Juez estime pertinente.

El Juez puede decidir que las multas acumulativas asciendan hasta el cien por ciento por cada dia calendario, hasta el acatamiento del mandato judicial.

El monto recaudado por las multas constituye ingreso propio del Poder Judicial, salvo que la parte acate el mandato judicial dentro de los tres días posteriores a la imposición de la multa. En este último caso, el monto recaudado será devuelto en su integridad a su titular". 
sentencias expedidas en los procesos constitucionales ${ }^{14}$ que causen "ejecutoria" -es decir que pongan fin al grado $o$ al proceso y que sean susceptibles de ejecución- se actúen conforme a sus propios términos, a fin de no permitir la monetarización del derecho constitucional, para evitar que se sustituya la restitución del derecho constitucional afectado por su equivalente en dinero. Y, más adelante, la norma se hace aun más especifica al señalar que la sentencia expedida en un proceso constitucional que establezca una condena de dar, hacer o no hacer, deberá cumplirse de manera inmediata, con lo cual queda claro que no solo la sentencia deberá ser cumplida conforme a lo estrictamente señalado en la parte resolutiva; sino que, además, podrá ejecutarse inmediatamente, es decir, a pesar de encontrarse impugnada.

Evidentemente, si en un proceso constitucional de hábeas corpus - destinado a tutelar los agravios a los derechos que conforman la libertad individual-se expide una sentencia estimatoria que concluye la detención indebida de un determinado sujeto y se ordena la liberación del mismo, qué duda cabe que el derecho protegido-libertad-es lo suficientemente relevante como para disponer la liberación inmediata del individuo, sin importar que la decisión haya sido objeto de apelación, dejando de lado la clásica suspensión de los efectos de la sentencia como consecuencia de la apelación.

Igual y evidente justificación podrá extraerse de un proceso constitucional de habeas data -que tutela el derecho a la libertad y acceso a la información-o de uno de amparo donde se ordene a quien agravie un derecho a cesar con la conducta gravosa o a cumplir con una determinada conducta. Condenar al agraviado a esperar la confirmación de la sentencia, resultará una imposición que no se condice con los procesos constitucionales entendidos como instrumentos cualificados de la tutela de urgencia. Ello debido a que -así como explicamos respecto a la actuación de la sentencia impugnada en los procesos con condena a una pensión de alimentos-, será más eficiente trasladar el costo de que la sentencia expedida en un proceso constitucional sea revocada $y, a$ pesar de ello, que se cumpla con el mandato de dar, hacer o no hacer contenido en ella, a que el demandante asuma el costo de esperar la confirmación de la sentencia que ordena un determinado acto tendiente a la protección del derecho constitucional afectado durante el trámite de la apelación, bajo riesgo, además, que dicha afectación devengue irreparable.

Es importante advertir que algunos jueces (guiados por un sector conservador de la doctrina nacional o por sus propios temores), se negaban a aceptar la realidad de la "actuación de la sentencia impugnada" en los procesos constitucionales, haciendo del artículo 22 del Código Procesal Constitucional una norma sin sentido y eficacia alguna. Felizmente, nuestro Tribunal Constitucional mediante la sentencia No. 5994-2005-PHC/TC evitó que la actuación inmediata de la sentencia constitucional estimatoria, sea letra muestra al establecer la siguiente jurisprudencia:

"(...) este Colegiado considera necesario enfa-
tizar que a diferencia del modelo procesal de la
derogada Ley No.23506 y normas conexas, el
Código Procesal Constitucional, vigente desde
el 1 de diciembre de 2004, ha incorporado para
los procesos de tutela de derechos el régimen
de actuación inmediata de sentencias, confor-
me al cual el juzgador se encuentra habilitado
para ejecutar los mandatos contenidos en su
sentencia estimatoria, independientemente de
la existencia de mecanismos de acceso a la ins-

"(...) este Colegiado considera necesario enfatizar que a diferencia del modelo procesal de la derogada Ley No.23506 y normas conexas, el Código Procesal Constitucional, vigente desde el 1 de diciembre de 2004, ha incorporado para los procesos de tutela de derechos el régimen de actuación inmediata de sentencias, conforme al cual el juzgador se encuentra habilitado on su la existencia de mecanismos de acceso a la ins-

14 El Código Procesal Constitucional Peruano regula los procesos i) de habeas corpus, ii) de amparo, iii) de habeas data, iii) de cumplimiento, iv) de acción popular, v) de inconstitucionalidad, vi) y competencial. Sin duda, la ejecución de la sentencia impugnada tendrá mayores posibilidades de uso en los proceso de habeas corpus, habeas data, amparo y cumplimiento en la medida que de estos derivan sentencias condenatorias. Sin embargo, y a fin de evitar pretender que el derecho sea el corsé de la realidad, se ha optado por reconocer la eventual aplicación del instituto a "los" procesos constitucionales sin restricción alguna. 
tancia superior. Bajo dicho marco referencial, no es aceptable, entonces, que bajo el pretexto del acceso a una instancia distinta por el lado de la contraparte, el juez constitucional renuncie a dar cumplimiento efectivo a su sentencia. Siésta es estimatoria tal condición es suficiente para franquear su actuación inmediata, no teniendo por qué esperar la culminación del proceso $(. . .)^{\prime \prime}$.

\section{Instituciones afines: medida cautelar temporal sobre el fondo}

Si bien el ordenamiento procesal peruano ha optado por una aplicación restringida del instituto, cierto es que los justiciables pueden recurrir a instrumentos que, si bien resultan distintos en cuanto a su finalidad respecto de la actuación de la sentencia impugnada, son coincidentes en cuanto a sus efectos asegurativos, evitando un daño irreparable.
Dentro del capítulo dedicado a la tutela cautelar, el Código Procesal Civil peruano distingue las medidas cautelares "temporales sobre el fondo"15 (satisfacción anticipada de la pretensión), de las medidas cautelares "innovativas", "de no innovar", "para futura ejecución forzada" y "genéricas".

Además de establecer los requisitos especiales necesarios para el otorgamiento de este tipo de medidas cautelares, el legislador prefirió a su vez regular determinados supuestos de hecho -no exclusivos ni excluyentes-, donde este tipo de medidas son procedentes. Así tenemos, por ejemplo:i) los casos de asignación de pensiones de alimentos ${ }^{16}$; ii) "cuando la pretensión principal versa sobre separación, divorcio, patria potestad, régimen de visitas, entrega de menor, tutela y curatela, procede la ejecución anticipada de la futura decisión final, atendiendo preferentemente al interés de los menores afectados por ella"17; iii) los procesos de desalojo ${ }^{18}$; iv) los

15 Articulo 674.- Medida Temporal sobre el fondo.-

"Excepcionalmente, por la necesidad impostergable del que la pide, por la firmeza del fundamento de la demanda y prueba aportada, la medida puede consistir en la ejecución anticipada de lo que el Juez va a decidir en la sentencia, sea en su integridad o sólo en aspectos sustanciales de ésta, siempre que los efectos de la decisión puedan ser de posible reversión y, no afecten el interés público". (Texto según Decreto Legislativo No. 1069).

16 Artículos 675 y 676 del Código Procesal Civil.

Artículo 675.- Asignación anticipada de alimentos.-

"En el proceso sobre prestación de alimentos procede la medida cuando es requerida por el cónyuge o por los hijos menores con indubitable relación familiar. El juez señalará el monto de la asignación que el obligado ha de pagar por mensualidades adelantadas, las que serán descontadas de la que se establezca en la sentencia definitiva".

Artículo 676.- Asignación anticipada y sentencia desfavorable.-

"Si la sentencia es desfavorable al demandante, queda éste obligado a la devolución de la suma percibida y el interés legal, los que serán liquidados por el Secretario de Juzgado, si fuere necesario aplicándose lo dispuesto por el Articulo 567. La decisión del Juez podrá ser impugnada. La apelación se concede con efecto suspensivo".

17 Artículos 677 y 680 del Código Procesal Civil. Artículo 677.- Asuntos de familia e interés de menores.

"Cuando la pretensión principal versa sobre separación, divorcio, patria potestad, régimen de visitas, entrega de menor, tutela y curatela, procede la ejecución anticipada de la futura decisión final, atendiendo preferentemente al interés de los menores afectados con ella.

Si durante la tramitación del proceso se producen actos de violencia fisica, presión psicológica, intimidación o persecución al cónyuge, concubino, hijos o cualquier integrante del núcleo familiar, el Juez debe adoptar las medidas necesarias para el cese inmediato de los actos lesivos, sin perjuicio de lo dispuesto en el Artículo 53".

Artículo 680.- Separación y divorcio.-

"En cualquier estado del proceso el Juez puede autorizar, a solicitud de cualquiera de los cónyuges, que vivan en domicilios separados, asi como la directa administración por cada uno de ellos de los bienes que conforman la sociedad conyugal".

18 Artículo 679 del Código Procesal Civil Artículo 679.- Desalojo.-

"En los procesos de desalojo por vencimiento del plazo del contrato o por otro titulo que obligue la entrega, procede la ejecución anticipada de la futura decisión final, cuando el demandante acredite indubitablemente el derecho a la restitución pretendida y el abandono del bien". 
procesos donde se discute la administración de bienes a fin de evitar un perjuicio irreparable ${ }^{19}$, $y$ v) en los interdictos de recobrar. ${ }^{20}$

La medida cautelar temporal sobre el fondo coincide con la actuación de la sentencia impugnada en tanto ambas conceden, a quien las solicita, la posibilidad de anticiparse al transcurso de determinadas etapas procesales. Sin embargo, la actuación anticipada de la sentencia impugnada tiene una finalidad satisfactiva: ejecutar aquello que ha sido declarado en sentencia atendiendo a la trascendencia del derecho tutelado; mientras que las medidas cautelares en general, incluyendo las temporales sobre el fondo, tienen una finalidad asegurativa: garantizar la eficacia de la sentencia.

En ese sentido, ambos institutos no son excluyentes, pues puede solicitarse una medida temporal sobre el fondo -finalidad asegurativa provisional- $y$, llegada la etapa procesal correspondiente, reclamarse que la sentencia estimatoria sea actuada a pesar de haber sido apelada, o de encontrarse pendiente el plazo para hacerlo -finalidad satisfactiva provisional-.

Otra distinción fundamental radica en el hecho que, mientras el instituto de la actuación de sentencia impugnada suele reservarse a determinados casos donde el interés va más allá de lo patrimonial, las medidas cautelares temporales sobre el fondo pueden ser aplicables a conflictos de contenido exclusivamente patrimonial. En ese sentido, queda claro que si bien el ordenamiento peruano ha optado por la aplicación del instituto para supuestos socialmente relevantes, cierto es también que el riesgo de irreparabilidad en aquellos conflictos de contenido netamente patrimonial también ha sido contemplado al regular las medidas cautelares temporales sobre el fondo.

\section{LA ACTUACIÓN DE LA SENTENCIA IMPUGNADA EN EL PERÚ FUTURO}

Son dos las principales propuestas de reforma que han contemplado introducir la actuación de la sentencia impugnada al ordenamiento procesal civil peruano. La primera reforma fue propuesta por la Comisión Especial para la Reforma Integral de la Administración de Justicia (Ceriajus), y la segunda consiste en una propuesta de reforma del Recurso de Casación que se encuentra ante la Comisión de Justicia del Congreso de la República.

Es importante mencionar que el principal impulsor para la recepción legislativa de tal instrumento de actuación procesal es el profesor Juan Monroy Gálvez.

\section{Ceriajus}

Constituida el 4 de octubre de 2003 por el Congreso de la República, la Ceriajus y, específicamente, el Grupo de Trabajo sobre Códigos y Normas Concretas establecieron diversas propuestas de reforma procesal aplicables a distintos cuerpos normativos. Entre las propuestas desarrollas podemos apreciar la modificación de

19 Artículo 678 del Código Procesal Civil.

Árticulo 678.-Administración de bienes.-

"En los procesos sobre nombramiento y remoción de administradores de bienes, procede la ejecución anticipada de la futura decisión final a efecto de evitar un perjuicio irreparable".

20 Artículo 678.- Administración de bienes.-

"En los procesos sobre nombramiento y remoción de administradores de bienes, procede la ejecución anticipada de la futura decisión final a efecto de evitar un perjuicio irreparable".

Artículo 681 del Código Procesal Civil.

Artículo 681.- Devolución de bien en el despojo.-

"En el interdicto de recobrar, procede la ejecución anticipada de la decisión final cuando el demandante acredite verosimilmente el despojo y su derecho a la restitución pretendida". 
determinadas normas que regulan el recurso extraordinario de casación ${ }^{21}$, más precisamente, respecto a los efectos de la interposición del recurso.

De acuerdo con la regulación vigente, la interposición del recurso de casación -al igual que el recurso de apelación- suspende los efectos de la sentencia. La propuesta de Ceriajus consiste en la concesión del recurso de casación sin efecto suspensivo, lo cual permitiría la ejecución de la sentencia de segundo grado, siempre y cuando sea de condena, a pesar de encontrarse impugnada. ${ }^{22}$ Sin embargo, la reforma no se limita exclusivamente a la concesión del recurso de casación sin efecto suspensivo, porque además:

a) Se propone la posibilidad de suspender la actuación de la sentencia siempre que quien interpone el recurso de casación brinde garantía dineraria por el monto de la ejecución. ${ }^{23}$ b) Se propone que en los casos de sentencias que contienen más de una decisión, la parte resolutiva de condena pueda ser ejecutada a pesar de la interposición del recurso, siempre y cuando no esté condicionada por los decisorios restantes. ${ }^{24}$

c) Se propone excluir la actuación de sentencias declarativas o constitutivas que no requieran de un posterior proceso de ejecución de sentencia para su actuación. En ese sentido, la norma es cautelosa en la medida que no excluye per se la actuación de sentencias meramente declarativas o constitutivas en general, sino únicamente en aquellos casos donde no quepa ejecución forzada. De este modo, se deja la posibilidad de no restringir las peculiaridades que puedan suscitarse a partir del caso concreto. ${ }^{25}$

d) Se propone además un procedimiento para la actuación de la sentencia impugnada. ${ }^{26}$

21 El proceso civil peruano contempla una primera instancia, generalmente a cargo de los jueces especializados en lo civil, en donde se realiza la actividad postulatoria y probatoria. Lo decidido en esta primera instancia es susceptible de revisión en segundo grado por la Corte Superior, cuyo objeto consiste en el exclusivo análisis de la sentencia (hechos y derecho) y cuyo trámite, en principio, carece de actividad probatoria. Excepcionalmente -previo cumplimiento de requisitos formales como sustanciales-, las partes pueden interponer recurso de casación contra lo decidido en segundo grado. Dicho recurso se encuentra bajo la dirección de la Corte Suprema de la República.

22 La propuesta de reforma es la siguiente: Artículo 393.- Ejecución de la sentencia impugnada.-

"La interposición del recurso no suspende la ejecución de las sentencias de condena".

23 Artículo 393.I. Suspensión de la ejecución.-

"La Sala Superior que expidió la sentencia impugnada dispondrá, a iniciativa de parte y mediante auto inimpugnable, que la ejecución sea suspendida, total o parcialmente, siempre que se preste caución dineraria por el monto de la ejecución. Cuando la ejecución no tenga contenido patrimonial, la Sala determinará el monto de la caución dineraria atendiendo a criterios de equidad".

24 Artículo 393.II. Ejecución parcial de la sentencia.-

"Si la sentencia impugnada tuviera más de un decisorio y uno o más de ellos fuese de condena, estos podrán ser ejecutados, siempre que su actuación no esté condicionada a la adquisición de firmeza de los otros decisorios".

25 Articulo 393.III. Sentencias impugnadas no ejecutables.

"No procede la actuación de las sentencias meramente declarativas o constitutivas, como aquellas que se refieran a filiación, nulidad de matrimonio, nulidad de acto jurídico, resolución de contrato, separación por causal o divorcio, capacidad y estado civily, en general, todas las que no requieran para su actuación de un posterior proceso de ejecución".

26 725.1. Competencia, requisitos y procedimiento de la ejecución de la sentencia impugnada.-

"La ejecución prevista en el artículo 393 se realiza ante el Juez de la demanda, acompañando copia certificada de la sentencia de la Corte Superior y cumpliéndose el mismo trámite que para la ejecución de la sentencia, además de las prescripciones aqui indicadas.

Contra el mandato de ejecución, además de lo dispuesto en el articulo 718 , solo procede oposición sustentada en que la sentencia es inejecutable atendiendo a lo previsto en el articulo 393.II y 393./II.

Siel recurso de casación fuese declarado improcedente o infundado, la ejecución continuará si no hubiera concluido. 


\section{Proyecto de reforma elaborada por el profesor Juan Monroy Gálvez}

La segunda propuesta que contempla la posibilidad de actuar la sentencia impugnada se encuentra en el Proyecto de Reforma del Titulo XII, Capítulo IV del Código Procesal Civil, referido al trámite del recurso de casación.

Dicho trabajo propone la modificación de diversas normas que regulan la casación en el Perú y la posibilidad de ejecución de la sentencia impugnada mediante recurso de casación, con lo cual queda claro entonces que de implementarse cualquiera de los dos proyectos, la actuación de la sentencia impugnada en el Perú sería una institución aplicable a los pronunciamientos expedidos en segundo grado -cortes superiores- y no a los de primera instancia -juzgados especializados-.
Si bien ambas propuestas coinciden en la importancia del instituto y en la necesidad de su incorporación al sistema, también es posible apreciar ciertas diferencias de la segunda respecto de la primera:

a) Se deja de lado la posibilidad de constituir una garantía a fin de suspender la ejecución: Tal y como señalamos líneas atrás, la reforma propuesta por la "Ceriajus" incluía, en el artículo 393.l, la posibilidad de que el ejecutado ofreciera una garantía a fin de lograr la suspensión de la actuación de la sentencia impugnada mediante el recurso de casación.

b) Quien debe constituir una garantía es el ejecutante: Se propone la incorporación del artículo $719.1^{27}$ al Código Procesal Civil, a fin de establecer, como lo hacía el articulo 725.1 de la propuesta elaborada por la "Ceriajus",

Si se casara la sentencia materia de ejecución, concluirá esta con la presentación de copia simple de la cédula de notificación de la sentencia respectiva, certificada con la firma y sello del abogado del ejecutado. Sin perjuicio de ello, ante el mismo Juez y dentro de un plazo de quince dias posteriores a la notificación del auto que concluyó la ejecución, el ejecutado, acompañando medios probatorios documentales, puede pedir que se expida mandato para que el ejecutante reponga la situación al estado anterior al inicio de la ejecución, pague las costas y costos de la ejecución innecesaria y la reparación por los daños que esta hubiere ocasionado. Cuando la reintegración devengue en imposible, el ejecutado podrá incluir esta situación como parte de la liquidación de daños.

Lo dispuesto en el párrafo anterior se aplica también a los procesos de ejecución concluidos antes de la expedición de la sentencia casada. En este caso el plazo empieza a contarse desde que el ejecutado fue notificado con la sentencia.

En los incidentes regulados en los dos párrafos anteriores, no procede apelación con efecto suspensivo ni recurso de casación".

27 Artículo 719.I Requisitos y procedimiento de la ejecución de la sentencia impugnada.-

"El ejecutante pide el inicio de la ejecución adjuntando copia certificada de la sentencia de la Corte Superior y garantía dineraria por el monto de la condena. Si ésta no tuviera contenido patrimonial, el Juez, atendiendo a criterios de equidad, determinará el monto de la garantía.

En lo demás, se sigue el mismo trámite que para la ejecución de la sentencia firme, además de las disposiciones aquí indicadas.

Contra el mandato de ejecución, además de lo dispuesto en el artículo 718 , solo procede oposición sustentada en que la sentencia es inejecutable atendiendo a lo previsto en el artículo 393.l y 393.ll.

Si el recurso de casación fuese declarado improcedente o infundado, la ejecución continuará, liberándose la garantía otorgada.

Si se casara la sentencia, concluye la ejecución. A éste propósito, la Corte oficiará en el día al Juez de la ejecución, utilizando el medio técnico más expeditivo e idóneo. Luego de recibido el oficio, el ejecutado, acompañando medios probatorios documentales, puede pedir se expida mandato para que el ejecutante reintegre la situación al estado anterior al inicio de la ejecución, pague las costas y costos de a ejecución innecesaria y la reparación por los daños que ésta hubiere ocasionado. Si la reintegración deviene imposible, el ejecutado puede incluir ésta situación como parte de la liquidación de los daños.

Lo dispuesto en el párrafo anterior se aplica también a los procesos de ejecución concluidos antes de la expedición de la sentencia casada.

En los incidentes regulados en los dos párrafos anteriores no procede apelación con efecto suspensivo ni recurso de casación". 
un procedimiento para la ejecución de la sentencia impugnada.

c) Traslado del deber de notificar la Resolución que declara fundado el recurso de casación a la Corte Suprema: En la propuesta de la "Ceriajus" era el ejecutado quien asumía la carga de informar al Juzgado la expedición de una sentencia en casación que revoca o anula la expedida por el grado a fin que se suspenda la ejecución anticipada. De acuerdo con la propuesta más reciente, es la Corte Suprema, quien asume la carga de notificar en el día, para lo cual tendrá a su disposición el medio técnico que considere más eficaz.

d) Inexistencia de plazo para solicitar el reintegro: Finalmente, la nueva propuesta elimina el plazo de quince días dentro del cual el ejecutado -luego que se declaraba fundado el recurso de casación- podía solicitar el reintegro de lo pagado así como los daños que pudieran haberse causado con la actuación anticipada de la sentencia impugnada. En consecuencia, en caso hagamos nuestra dicha reforma, la solicitud de reintegro no estará sometida a restricción temporal alguna.

\section{v. CONCLUSIONES}

1. La ejecución provisional de la sentencia civil - actuación anticipada de la sentencia impugnada es un instituto que no se encuentra regulado en el ordenamiento procesal civil peruano, salvo para el caso específico de los procesos de familia donde se discuta el pago de la pensión de alimentos.

2. La escasa regulación se debe a dos motivos fundamentales: i) una justificada preocupación por aplicar cautelosamente el instituto, y ii) el interés por utilizarlo en aquellos conflictos donde se discuten más que intereses netamente patrimoniales, $\mathrm{o}$, dicho de otro modo, aplicar el instituto a conflictos de trascendencia social donde el costo de actuar una sentencia posteriormente revocada sea menor que el costo de esperar a que la sentencia se confirme.

3. La actuación anticipada de la sentencia impugnada sí encuentra reconocimiento en los procesos constitucionales donde se expidan mandatos de dar, hacer o no hacer, privilegiando la concepción de que la actuación de la sentencia impugnada es posible únicamente en las sentencias de condena.

4. Si bien la actuación anticipada de la sentencia impugnada sigue teniendo un reconocimiento limitado, es posible obtener tutela asegurativa mediante medidas cautelares temporales sobre el fondo. Sin duda se trata de un instituto distinto, no es satisfactivo; sin embargo, permite evitar que el transcurso del tiempo cause la irreparabilidad del derecho de quien acude al proceso precisamente en busca de tutela.

5. Aparentemente el futuro del instituto viene acompañado de reformas que proponen su aplicación en el marco del recurso extraordinario de casación. En ese sentido, se busca restar el efecto suspensivo que acompaña al recurso de casación, y permitir que la sentencia sea actuada antes que la Corte Suprema emita pronunciamiento. Dicha reforma debe ir de la mano de un reforzamiento de las cortes superiores de modo tal que sea mayor el numero de sentencias emitidas en segundo grado -actuadas anticipadamentey confirmadas (en sede casatoria), respecto de aquellas que son revocadas.

6. Por ello, de manera simultánea a la reforma procesal, es imperativo que nos avoquemos a diseñar una nueva corte superior para nuestro país. Si se piensa dar un paso en materia de actuación anticipada de la sentencia en sede civil, y para que este no sea en falso, es necesario que el juez superior o de revisión tenga una adecuada carga procesal, para que se le pueda exigir decisiones más justas y de calidad. 